NASA TECHNICAL MEMORANDUM
NASA TM X- 68099

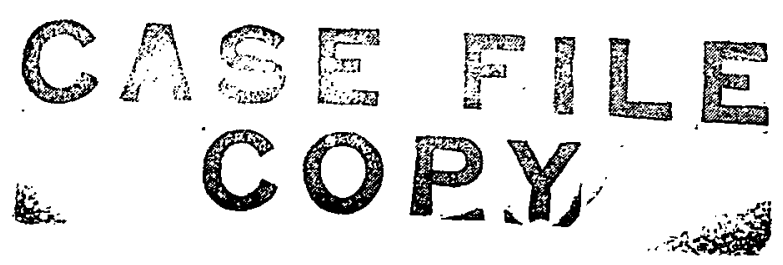

\title{
AN ANALYTICAL AND EXPERIMENTAL EVALUATION OF SHADOW SHIELDS AND THEIR SUPPORT MEMBERS
}

by Robert J.Stochl and Robert J. Boyle Lew is Research Center Cleveland, Ohio

TECHNICAL PAPER proposed for presentation at

1 Cryogenic Engineering Conference Boulder, Colorado, August 9-11, 1972 
AN ANALYTICAL AND EXPERIMENTAL EVALUATION OF SHADOW SHIELDS AND THEIR SUPPORT MEMBERS

By Robert J。 Stoch1 and Robert J。 Boyle

Lewis Research Center

National Aeronautics and Space Administration

Cleveland, Ohio.

\begin{abstract}
Experimental tests were performed on a model shadow shield thermal protection system to examine the effect of certain configuration variables. The experimental results were used to verify the ability of an analytical program to predict the shadow shield performance including the shield-support interaction. In genera1, the analysis (assuming diffuse surfaces) agreed well with the experimental support temperature profiles. The agreement for the shield profiles was not as good. The results demonstrated

(1) shadow shields can be effective in reducing the heat transfer into cryogenic propellant tanks, (2) the conductive heat transfer through supports can be reduced by selective surface coatings.
\end{abstract}




\section{AN ANALYTICAL AND EXPERIMENTAL EVALUATION OF SHADOW SHIELDS AND THEIR SUPPORT MEMBERS}

By Robert J. Stochl and Robert J. Boyle

\section{INTRODUCTION}

For 1ong duration interplanetary missions involving cryogenic propellants, it becomes necessary to reduce the heat flux into propellant tanks to extremely low values. Radiation is a significant mode of heat transfer in space. Two forms of radiation barriers which effectively reduce radiant heat transfer are multilayer insulation, which consists of many closely spaced, highly reflective layers separated by low conducting spacers, and shadow shields, consisting of few layers, but spaced farther apart to allow heat to escape to surrounding space. Studies have shown (ref. 1-3) that if the major radiant heat load is unidirectional, such as for a sun oriented spacecraft, shadow shields can provide performance superior to multilayer insulation.

To date, analytical and experimental studies of shadow shield performance (ref. 4-5) have been largely confined to idealized, freefloating shields with little effort being devoted either analytically or experimentally to the thermal interaction between shields and their support structures.

This paper presents the major results of a program undertaken to (1) develop an analysis which would include the strut-sheild interaction in predicting shadow shield performance, (2) experimentally examine the effect of configuration variables on the performance of a scale model shadow shield system, (3) use the experimental results to verify the analysis.

\section{EXPERIMENTAL APPARATUS}

The experimental apparatus consisted of a payload simulator, a propellant tank, shadow shields and their support struts, and instrumentation to record temperatures and heat-transfer rates.

A11 experimental tests were performed inside a vacuum chamber in an attempt to eliminate gaseous conduction. The test tank, shadow shields, struts and payload simulator were suspended from the top cover of a liquid hydrogen cryoshroud as shown schematically in Figure 1a, and pictorially in Figure 1b. The test tank was constructed of copper and had a diameter of 1.27 meters $(4 \mathrm{ft}$, ). The exterior of the tank was covered with aluminum foil to provide a surface of known emissivity 
( $\epsilon=0.03$ at room temperature). The tank contained either liquid hydrogen or liquid nitrogen during a test sequence. An aluminum ring, attached to the midsection of the tank, connected the struts to the tank.

Directly above the test tank was a cold guard containing the same fluid as the test tank. The purpose of this guard was to eliminate solid conduction through support tubes, fill and vent lines and instrumentation wires.

Twelve evenly spaced, tubular struts were used to suspend the shadow shields and payload simulator from the test tank. Both titanium and fiberglass struts were used. The diameter of each strut was $2.22 \mathrm{~cm}$ $(0.875 \mathrm{in})$ with a wall thickness of $0.038 \mathrm{~cm}(0.015 \mathrm{in})$. The strut length between payload simulator and tank was 0.56 meters $(22.0$ in). Radiation disks made from aluminum foil were installed in each strut to prevent longitudinal radiation inside each strut. Three strut configurations were used (fig. 2), (1) all black; exterior surface painted with a high emissivity paint, (2) half black; outward facing half of strut painted, inward half coated with aluminized mylar, (3) insulated with five layers of aluminized mylar, with silk net spacers between each layer.

The shadow shields were 1.37 meters (54 in) in diameter. Each shield consisted of a sheet of nylon reinforced, double aluminized mylar stretched across and laced to each side of a $1.91 \mathrm{~cm}(0.75 \mathrm{in})$ thick circular ring. The average measured emissivity value of the sheet material was 0.03 . Figure 3 illustrates a detail of a shield where a strut passes through the shield. The shields were attached to the struts through a bushing, aluminum block arrangement. Aluminum and micarta bushings were evaluated.

The payload simulator (heater) consisted of a 1.37 meter (54 in) diameter, $0.318 \mathrm{~cm}(0.125 \mathrm{in})$ thick aluminum plate. Electric heaters were bonded to the side facing away from the tank. The other side was coated with a high emissivity paint.

The whole test configuration (fig. 1) was placed inside a cylindrical liquid hydrogen cooled cryoshroud. The inside surfaces of the cryoshroud were coated with a high absorptivity paint to simulate the enviromment of deep space. Liquid hydrogen cooled baffles were placed adjacent to the shields and heater to prevent reflected energy from reaching the test tank.

A series of mass flowmeters was used to record the boiloff from the tank. The boiloff rate was used to determine the heat-transfer rate into the test tank. Thermocouples and platinum resistance sensors were used to determine temperatures of the shields, struts, heater, test tank and cryoshroud. Vacuum gages were used to determine pressures inside and outside of the cryoshroud. 


\section{PROCEDURE}

In a typical experimental run, the chamber was evacuated to approximately $1 \times 10^{-5} \mathrm{~mm} \mathrm{Hg}$. The temperature of the heater was set and controlled at the desired value--either $294^{\circ} \mathrm{K}$ or $3890 \mathrm{~K}\left(530^{\circ} \mathrm{R}\right.$ or $\left.7000^{\circ} \mathrm{R}\right)$. The cryoshroud was then cooled to approximately $22^{\circ} \mathrm{K}\left(40^{\circ} \mathrm{R}\right)$ with liquid hydrogen. The test tank and cold guard were filled with either liquid hydrogen or liquid nitrogen. The pressure inside the test tank and cold guard were maintiained at $11.376 \times 10^{4}$ and $11.411 \times 10^{4}$ Newtons/ $\operatorname{meter}^{2}\left(16.50\right.$ and $\left.16.33 \mathrm{lb} / \mathrm{in}^{2}\right)$ respectively, by a back pressure control system capable of controlling pressure to within +1.379 Newtons/meter ${ }^{2}$ $\left(0.0002 \mathrm{lb} / \mathrm{in}^{2}\right)$ : The test configuration was maintained at these conditions until the boiloff and all strut and shield temperatures stabilized.

\section{ANALYTICAL MODEL}

The analytical modei for which the results will be presented was specifically tailored to the test configuration shown in Figure 1 . The complete analysis, too lengthy to be presented in detail here, will be briefly sümarized.

The struts, shields, test tank and payload simulator are divided into a series of nodes. The temperature profiles for the struts and shields are found by equating the net rate at which heat is absorbed by a node element to the rate of change of thermal capacitance of the node element. Heat is transferred into a nodal element by radiation and conduction. Figure 4 shows the major heat transfer terms which were considered in the analysis of the sheet and strut nodes. The equations were solved iteratively starting with the surfaces nearest the heater. The number of nodes were increased until there was no change in the temperatures with a further increase in the number of nodes. Typically, this resulted in twelve nodes for each sheet and twenty along the length of the struts. This analysis assumes that there is no radial temperature gradient in the wall of the struts and no circumferential gradient in the shields. All surfaces are assumed to be gray, opaque, and to emit and reflect energy diffusely. The radiant interchange between all the nodes is calculated using Hottel!'s script $F$ method described in reference 6. The view factors needed in this method were found numericaliy using the computer program described in reference 7. To minimize the number of nodes required and thereby reduce the computer time involved in performing the thermal analysis, the nodal network was broken up into a series of enclosures. The enclosures chosen for the analysis corresponded to the physical enclosures of the test configuration. For example, in a test with no shields; only a single enclosure is defined. The twelve struts, the surface of the heater and the surface of the tank facing the heater are in the enclosure. The surface of the baffle and 
the cryoshroud between the plane of the heater and the plane at the start of the tank cylindrical section complete the enclosure. When two shields are present, a total of five enclosures are used with no enclosure containing more than two sheet surfaces. The solution to the energy balance as applied to each node in a particular enclosure is carried out using the CINDA-3G computer program as described in reference 8.

\section{RESULTS AND DISCUSSION}

The complete matrix of tests that were performed is shown in Table I. For the sake of brevity, the data presented herein will be based on the results obtained for test configurations 1,2 and 6 , using liquid hydrogen in the test tank. Where possible, the results will be presented for the higher heater setting because of its magnification of the radiation component.

\section{Struts Alone \\ (Configuration 非)}

For the test without shields, half of the 12 struts were titanium and half were fiberglass. For each material, there was one insulated strut, one all black strut and four half black struts. Thermocouples were placed and centered on both the outward and imward sides of the half black struts.

Figure 5 presents a comparison between the analytic and experimental temperatures for the half black titanium struts. Throughout the testing, there was good agreement between thermocouple readings on struts of the same configuration. Therefore, it was felt that there is no need to distinguish thermocouple readings for different struts of the same configuration. As seen in Figure 5, there is experimental evidence of a circumferential gradient from near zero to a maximum of $22^{\circ} \mathrm{K}\left(40^{\circ} \mathrm{R}\right)$. Analytically, there is a circumferential gradient only along the warm end of the strut. Two analytic curves are presented for each part of this figure. One curve is based on using a single circumferential node and gives no information as to a possible circumferential gradient. The other curve is based on using two circumferential nodes, and yields an axial temperature distribution for both the inward and outward halves of the strut. This analysis considers both circumferential conduction and black body internal cross radiation between the outward and inward halves of the strut. The analysis underpredicts the temperature profile at the cold end of the strut, but agrees in shape with the experimental data.

Figure 6 presents the temperature profiles for the fiberglass struts for the same conditions presented for the titanium struts. There is experimental evidence of a significant circumferential gradient for these 
half black struts (fig. 6). Analytically, the outward half profile for 2 nodes is coincident with the single node profile. The inward half profile is slightly warmer.

Comparing the results shown in Figures 5 and 6 indicates that the axialitemperature gradient at the tank end of the struts is nearly the same for the titanium and fiberglass struts and is largely determined by radiant energy interchange! This implies a greatly reduced heat flux into the test tank for the fiberglass strut due to its lower thermal conductivity. Although not shown here, the all black struts exhibited a cold end temperature gradient 2 to 4 times greater than that of the half black struts. The insulated strut produced a near linear temperature gradient between the heater and tank and a heat transfer rate about half that of the half black struts.

\section{Heat Transfer Results}

A comparison of experimental and analytic heat transfer rates without shields is presented in Table IIa. Results are given for the two payload temperatures with liquid hydrogen in the test tank. The total experimental heat flux rate into the test was determined from the boiloff measurements. The values given for the conductive heat transfer rate were obtained from the experimental axial temperature gradient at the cold end coupled with the analytic value for thermal conductivity. The radiant heat transfer rate is then assumed to be the difference between the total heat transfer rate and the conductive component. As can be seen, the conductive component is relatively small in comparison with the total and there is good agreement between the experimental and the analytic values. Even though only half the struts were titanium, they contribute approximate1y $90 \%$ of the conduvtive heat transfer rate.

The gray surface analysis greatly underpredicts the amount of radiant heat transfer into the tank. The radiant energy absorbed is almost linearly dependent upon the tank surface absorptivity. The absorptivity, in reality, is a function of the temperature of the incoming radiation. The gray surface assumption ignores this dependency and lets the tank absorptivity equal its emissivity, which at liquid hydrogen temperature is very low. Therefore, for the no shield tests where the temperature differences were large, the analysis was modified to account for nongray effects. The tank emissivity was taken to be that of the aluminum foil at tank temperature while the absorptivity corresponded to that of aluminum foil at the heater temperature. These results are also shown in Table IIa and are in much better agreement with the experimental data.

Struts with Shields

(Configurations 2 and 6)

The next figures present the results obtained with two shields, evenly spaced, between the heater and the test tank. The centerline 
distance from the heater to the tank was $31.75 \mathrm{~cm}(12.5 \mathrm{in})$.

Figure 7 presents a comparison between the analytic and experimental temperatures for the half-black titanium struts. These particular results are for a payload temperature of approximately $298^{\circ} \mathrm{K}\left(536^{\circ} \mathrm{R}\right)$. As can be seen, the temperature profiles with shields are significant1y altered from those without shields, with a reduced axial gradient at the cold end. Also, there is very little experimental evidence of a circumferential gradient. Analytically, there is no evidence of a circumferential gradient. As a result, only the one node analytic result is presented. In general the analysis agrees well with the experimental data.

Recall that without shields, the insulated strut produced a lower gradient at the tank than the half black struts. However, with shields, the half black strut has a lower gradient at the tank. As a result, it would not be beneficial, as far as seducing the conduction component, to insulate the struts in the presence of shields.

Figure 8 presents the data for the half black fiberglass struts for a payload temperature of $389^{\circ} \mathrm{K}\left(700^{\circ} \mathrm{R}\right)$. Here again, there is little experimental evidence of a circumferential gradient except near the warm end. In comparing the cold end gradients in figures 6 and 8 , it can be seen that the gradient for the fiberglass strut is greatly reduced in the presence of shields. The analyses underpredicts the axial strut profile for the entire. length of the strut, possibly because of the contact resistance, but the analytic shape agrees well with the experimental data.

\section{Shields}

Figure 9 presents radial temperature profiles for each sheet of each shield. The data presented are for a payload temperature of $389^{\circ} \mathrm{K}$ $\left(700^{\circ} \mathrm{R}\right)$. Thermocouples were placed on the inside of one sheet for each shield at three radial and two circumferential positions. Additional thermocouples were placed on the outside of each sheet at corresponding radial positions.

The experimental data shown in Figure 9 indicate relatively constant radial temperatures for each sheet. There is good agreement between the analysis and the outside thermocouples of the warmest sheet. The experimental temperature difference between sheets of the warmer shield is greater than the analytic difference. The analysis would predict a difference of this magnitude only if the ring were transpar- 
ent and the inside surface of the shields could radiate to the cryoshroud. A supposition could be made that the ring absorbed a great deal of the emitted energy from the warm sheet. This would tend to lower the temperature of the cooler sheet and raise the ring temperature.

The analysis overpredicts the temperatures for both sheets of the colder shield. These temperatures are a strong function of the sheet temperatures of the warm shield. Although it is not. shown on the figure, adjusting the analytic temperatures for the warmer shield to the experimental values would result in analytic temperatures which are in good agreement with the experimental data for the colder shield. Also, an analysis was performed considering directional properties of the aluminized surface. This reduced the interchange factor between the sheets of different shields. As can be seen by the dashed curves on Figure 9, the resulting thermal analysis yielded only small changes in the sheet temperatures for the warmer shield. However, the analytic temperatures for both sheets of the colder shield were in much better agreement with the experimental values.

\section{Heat Transfer Results}

The total heat flux into the test tank when using the shadow shields was extremely low (less than $1 \mathrm{BTU} / \mathrm{hr}$ ). At these low values, any stray or unaccountable heat input into the test tank would greatly effect any comparisons between experimental and analytic heat transfer results. Nul1 tests were performed in an attempt to determine the magnitude of possible stray heat paths into the test tank. These tests were conducted with both the test tank and payload simulator at liquid hydrogen temperatures for several vacuum levels. The results of these null tests indicated a stray heat flux of between 0.10 watts $(0.34 \mathrm{BTU} / \mathrm{hr})$ and 0.60 watts $(2.05 \mathrm{BTU} / \mathrm{hr})$ depending on the vacuum level $\left(1 \times 10^{-6}\right.$ to $7 \times 10^{-5} \mathrm{~mm}$ $\mathrm{Hg}$ ). These heat fluxes are of the same magnitude that was measured for the two payload temperatures. The total experimental heat flux values presented in Table IIb were obtained by subtracting the null test values from the measured values obtained for the two payload temperatures. As can be seen in this table, between 0.04 watts $(0.135 \mathrm{BTU} / \mathrm{hr})$ and 0.059 watts $(.200 \mathrm{BTU} / \mathrm{hr})$ can be attributed to the heat flux from the heater, depending on payload temperature and strut material. Of these net heat flux values, between 0.008 watts $(0.028 \mathrm{BTU} / \mathrm{hr})$ and 0.055 watts $(0.186$ $\mathrm{BTU} / \mathrm{hr}$ ) is by conduction through the fiberglass and titanium struts, respectively. Although there is a large uncertainty associated with these values, making quantitative comparisons meaningless, they do show the effectiveness of using shadow shields as a thermal protection system. The heat flux values are at least an order of magnitude less than would be obtained using many layers of multilayer insulation.

For the conditions presented, the analysis predicts a total heat flux ranging between 0.005 watts $(0.016 \mathrm{BTU} / \mathrm{hr})$ and 0.131 watts $(0.445$ $\mathrm{BTU} / \mathrm{hr}$ ) depending on payload temperature and strut material. of these 
total values, approximately $60 \%$ is by conduction when using fiberglass struts and approximate ly $98 \%$ by conduction when using titanium struts.

\section{CONCLUDING REMARKS}

In general, there is good agreement between the experimental strut profiles and the corresponding analytic predictions. As would be expected, the agreement is better for the titanium struts than for the lower conducting fiberglass struts.

The agreement between the analytic and experimental shield temperatures is not quite as good. The diffuse analysis overpredicts the shield temperatures and hence gives a conservative prediction for the radiant heat transfer. Better agreement with the experimental shield temperatures was obtained when the diffuse model temperatures were corrected for specular effects.

The experimental and analytic results show that shadow shields can be effective in reducing the heat transfer into a cryogenic propellant tank. In addition to essentially eliminating the radiation component, the conductive heat transfer can be substantially reduced. This is accomplished by coating the struts to achieve a high emissivity and letting them radiate to space. Conversely, in the absence of shadow shields, the conductive heat transfer is reduced by insulating the struts to avoid radiant energy from the payload from being absorbed at the cold end of the strut and then conducted into the tank.

\section{REFERENCES}

1. Hall, Charles F.; Nothwang, George, J.; and Hornby, Harold: Solar Probes - A Feasibility Study. Aerospace Eng., vol. 21, no. 5, May 1962, pp. 22-30.

2. Lundholm, J. G., Jr.; Prohaskka, E. S.; Hoyer, S.; and Averell, J.: A Close Approach Solar Probe Design Feasibility and Mission Study. Paper 64-496, AIAA, June 1964.

3. Smolak, George, R.; Knoll, Richard H.; and Wallner, Lewis E.: Analysis of Thermal-Protection Systems for Space-Vehicle Cryogenic-Propellant Tanks. NASA TR R-130, 1962.

4. Knoll, Richard H.; and Bartoo, Edward R.: Experimental Studies on Shadow Shields for Thermal Protection of Cryogenic Tanks in Space. NASA TN D-4887, 1968. 
5. Boyle, Robert J.; and Knoll, Richard H.: Thermal Analysis of Shadow Shields and Structural Members in a Vacuum. NASA TN D-4876, 1968.

6. Wiebelt, J. A.: Engineering Radiation Heat Transfer. Holt, Rinehard and Winston, Inc., 1966.

7. Dummer, R. S.; and Breckenridge, W. T., Jr.: Ratiation Configuration Factors Program. Rep. ERR AN-224, General Dynamics/Astronautics, Feb. 1963.

8. Lewis, D. R.; Galski, J. D.; and Thompson, L. R.: Chrysler Improved Numerical Differencing Analyzer for Third Generation Computers.

Rep. TN-AP-67-287, Chrysler Corp. (NASA CR-99595), Oct. 20, 1967. 


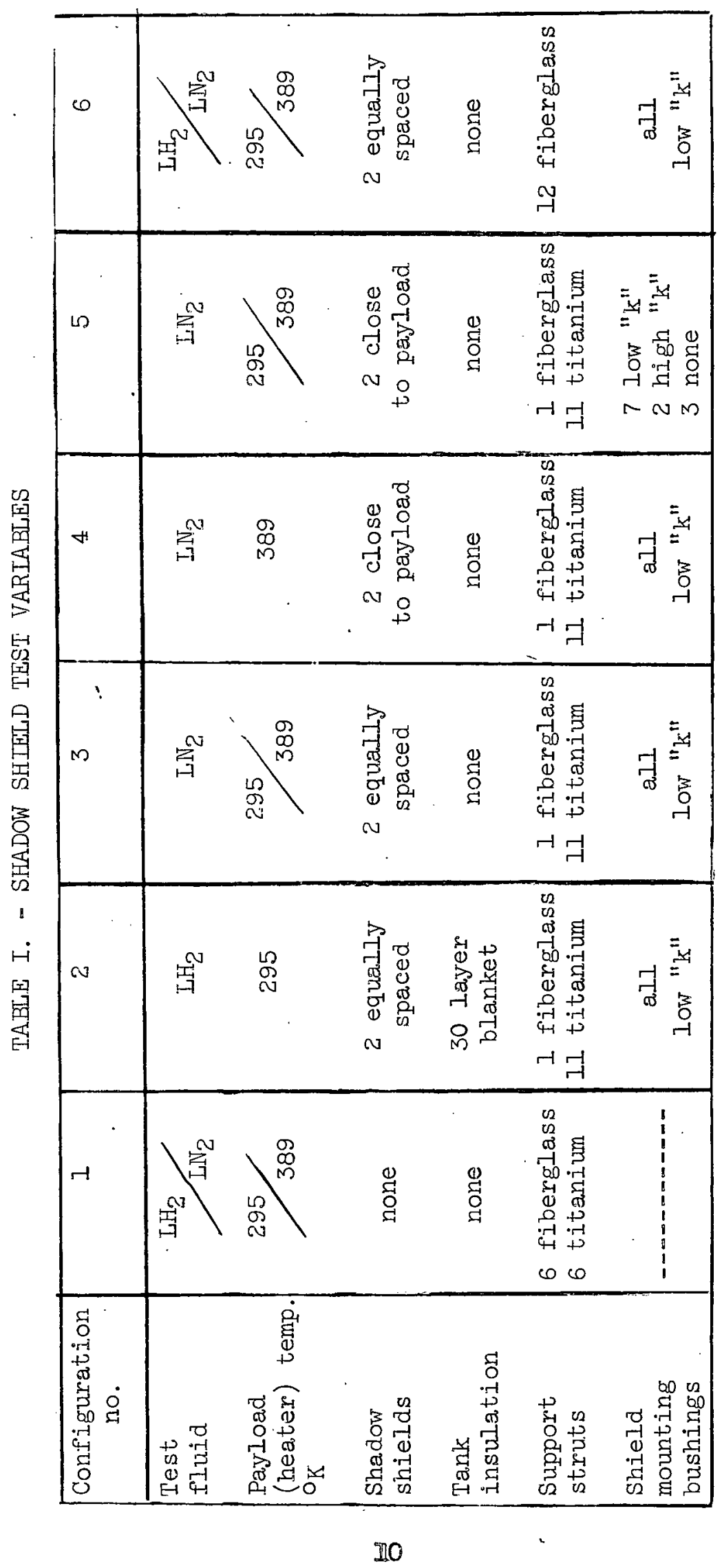



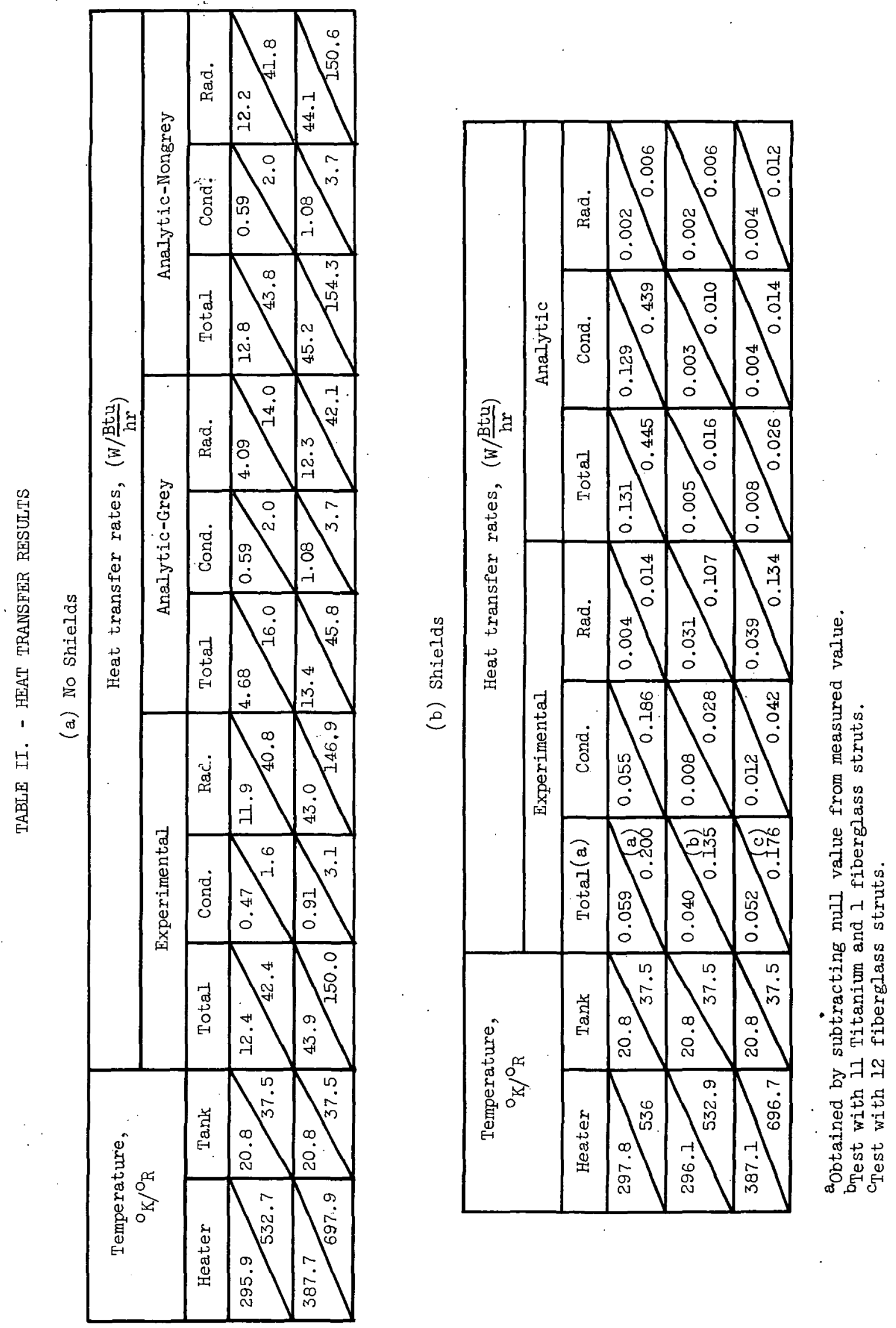


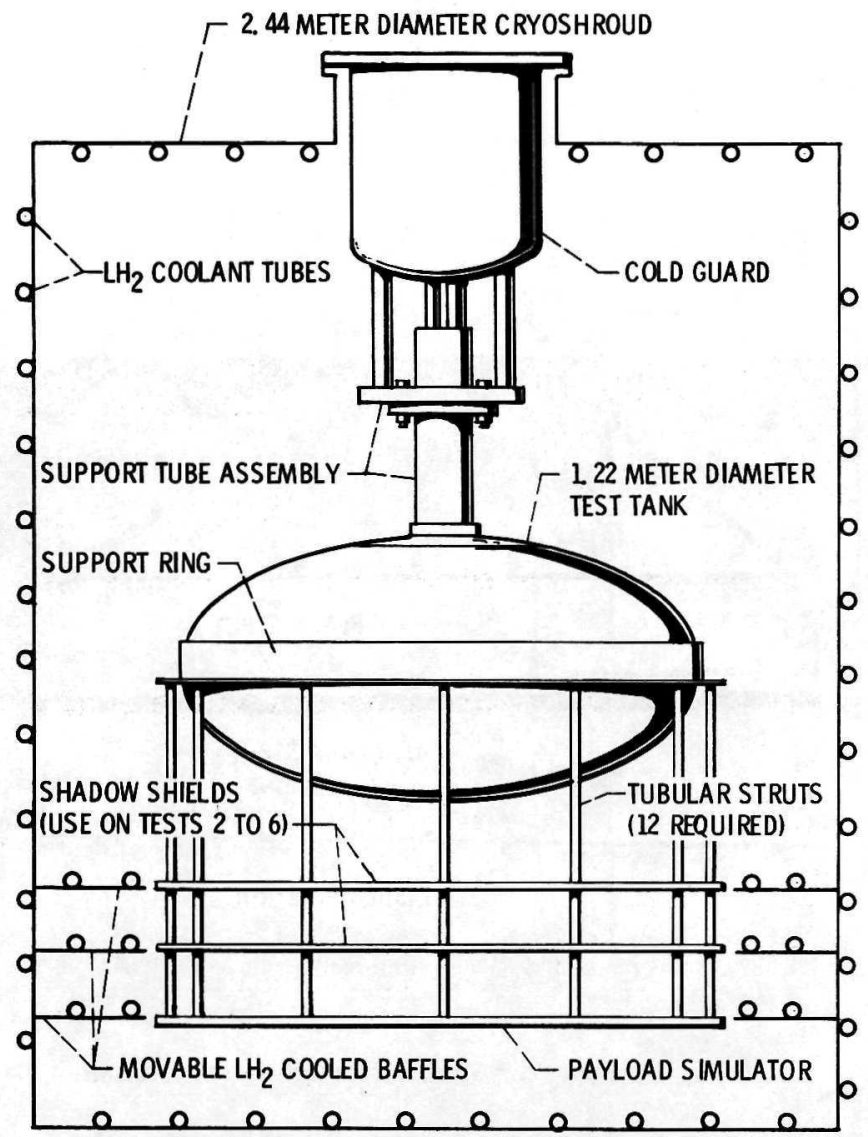

(a) GENERAL TEST CONFIGURATION.

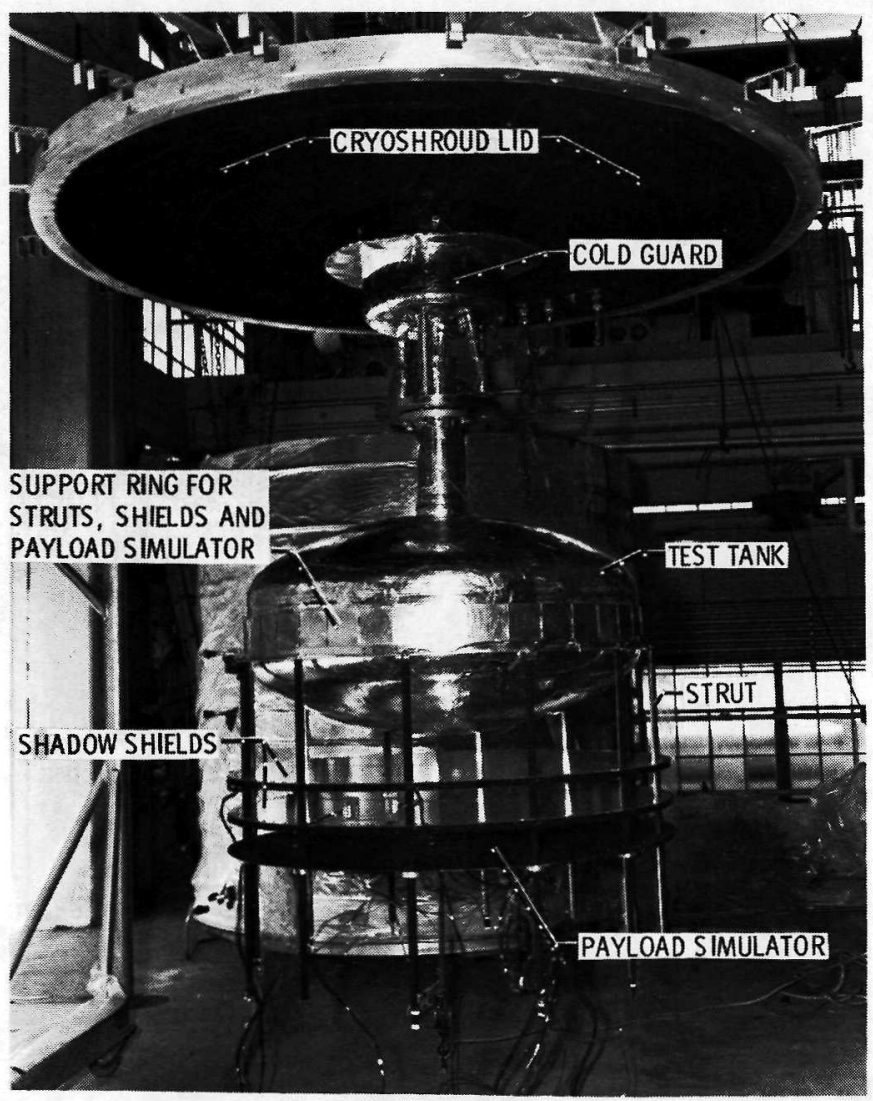

(b) TEST CONFIGURATION.

Figure 1 


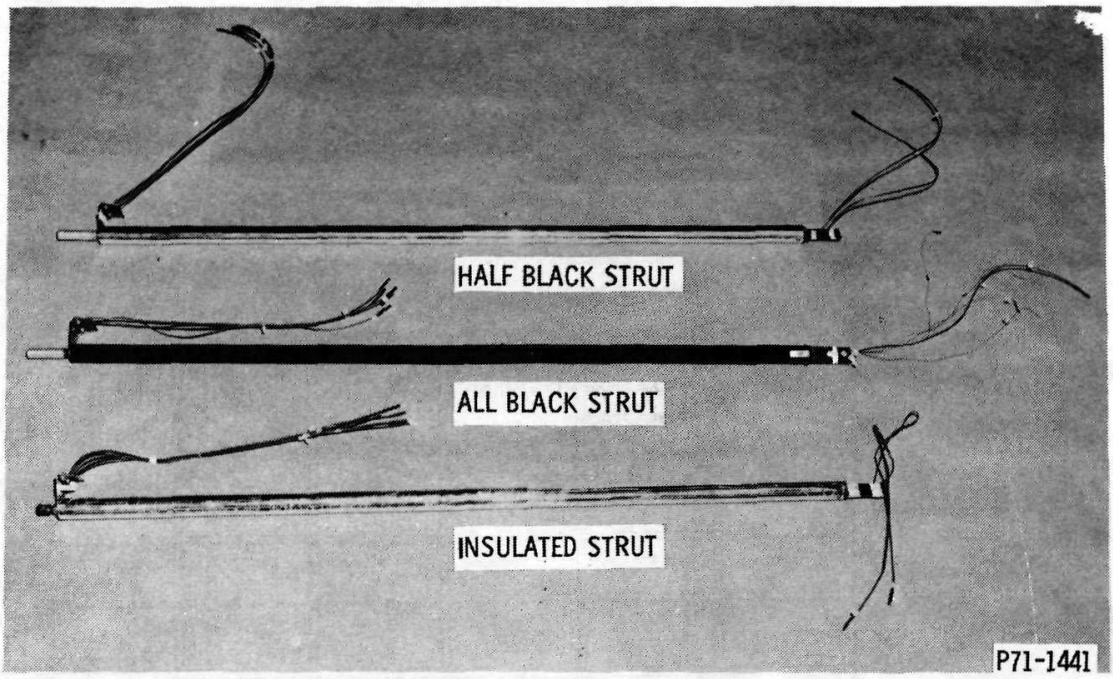

Figure 2. - Strut surface coating configurations.

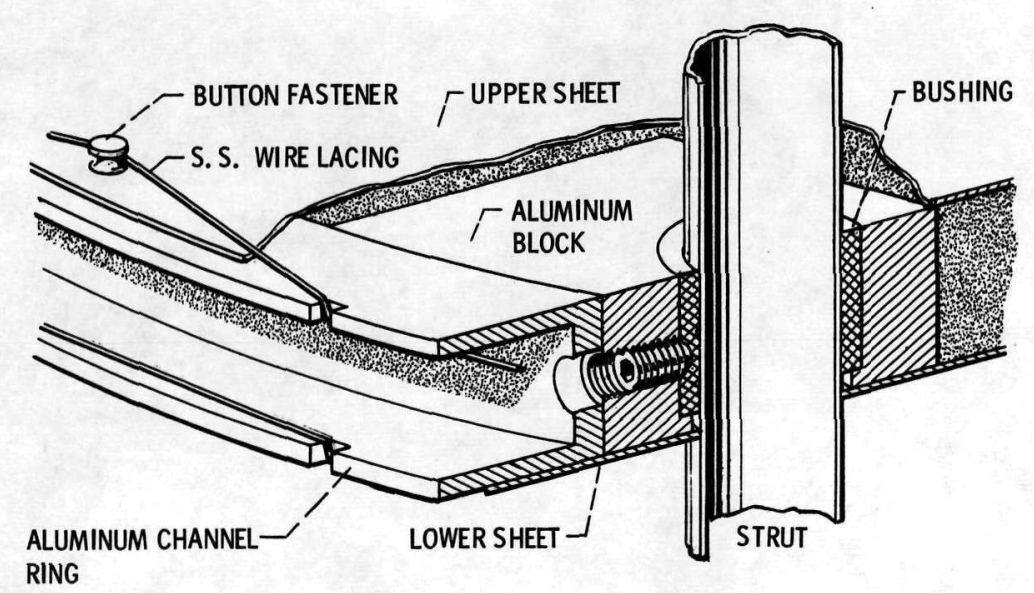

Figure 3. - Detail of strut to shield connection 


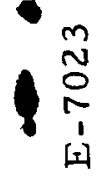

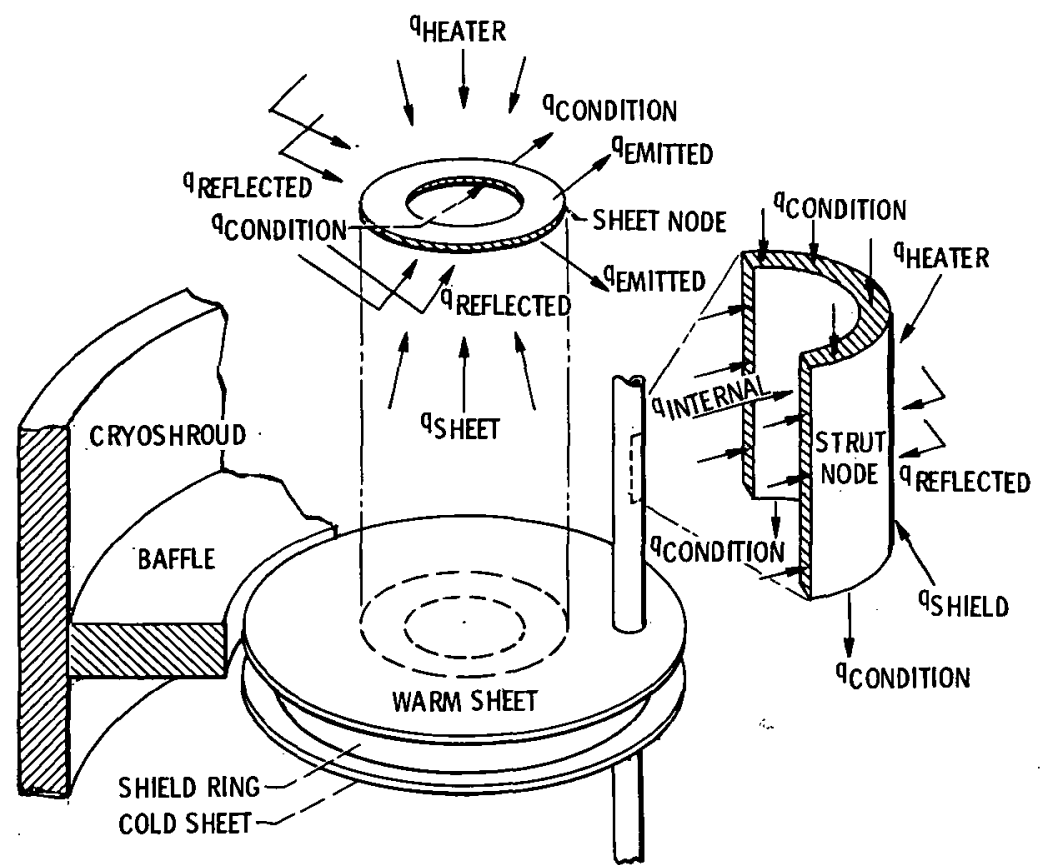

Figure 4. - Schematic of heat transfer terms for sheet and strut nodes.
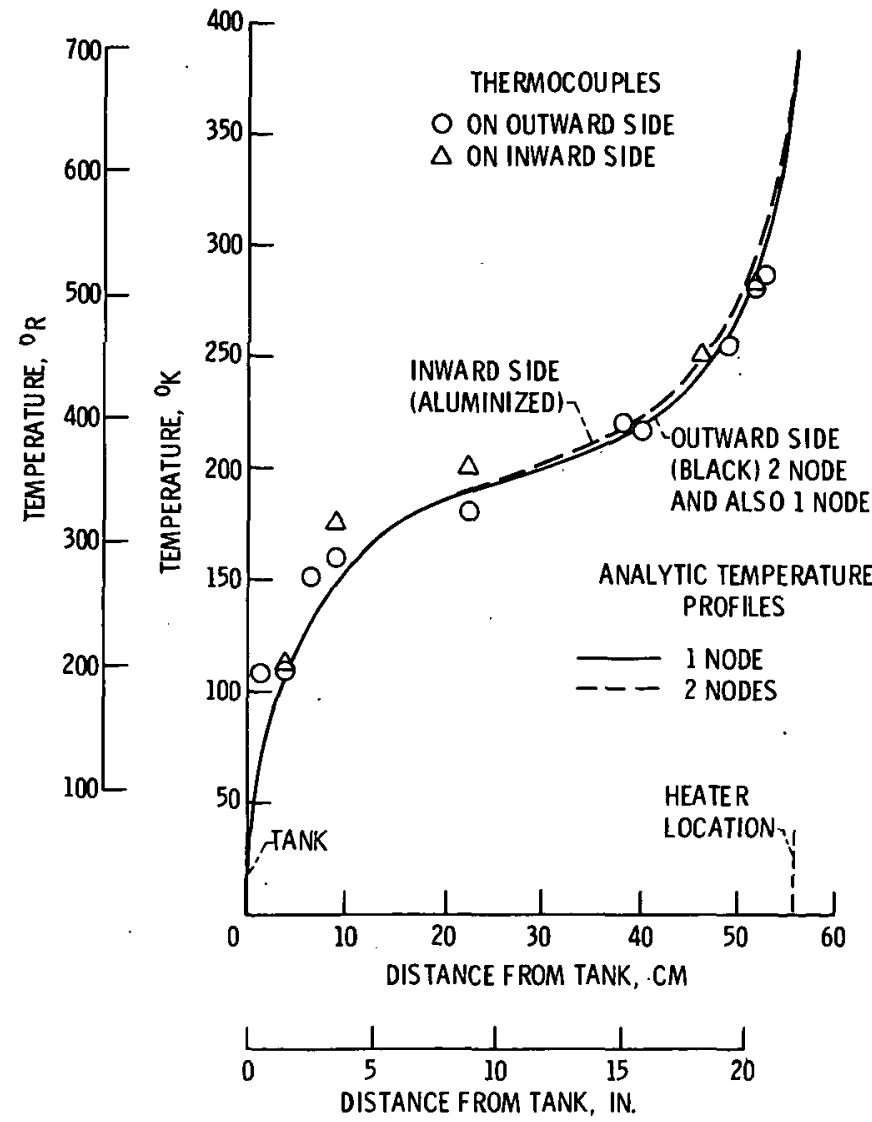

Figure 5. - Temperature profiles for half black titanium strut with no shieids, heater temperature $=388^{\circ} \mathrm{K}\left(698^{\circ} \mathrm{R}\right)$. 

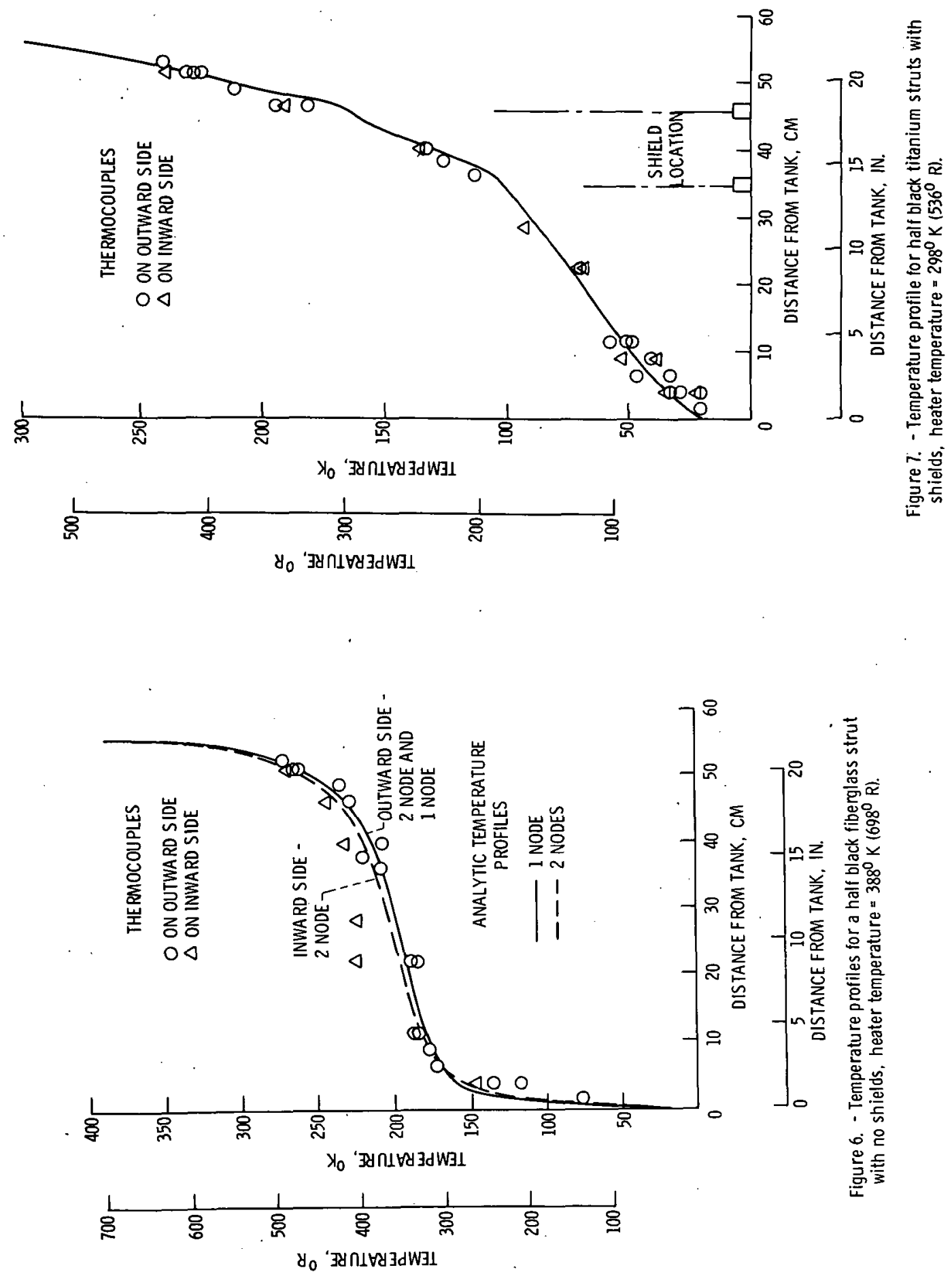

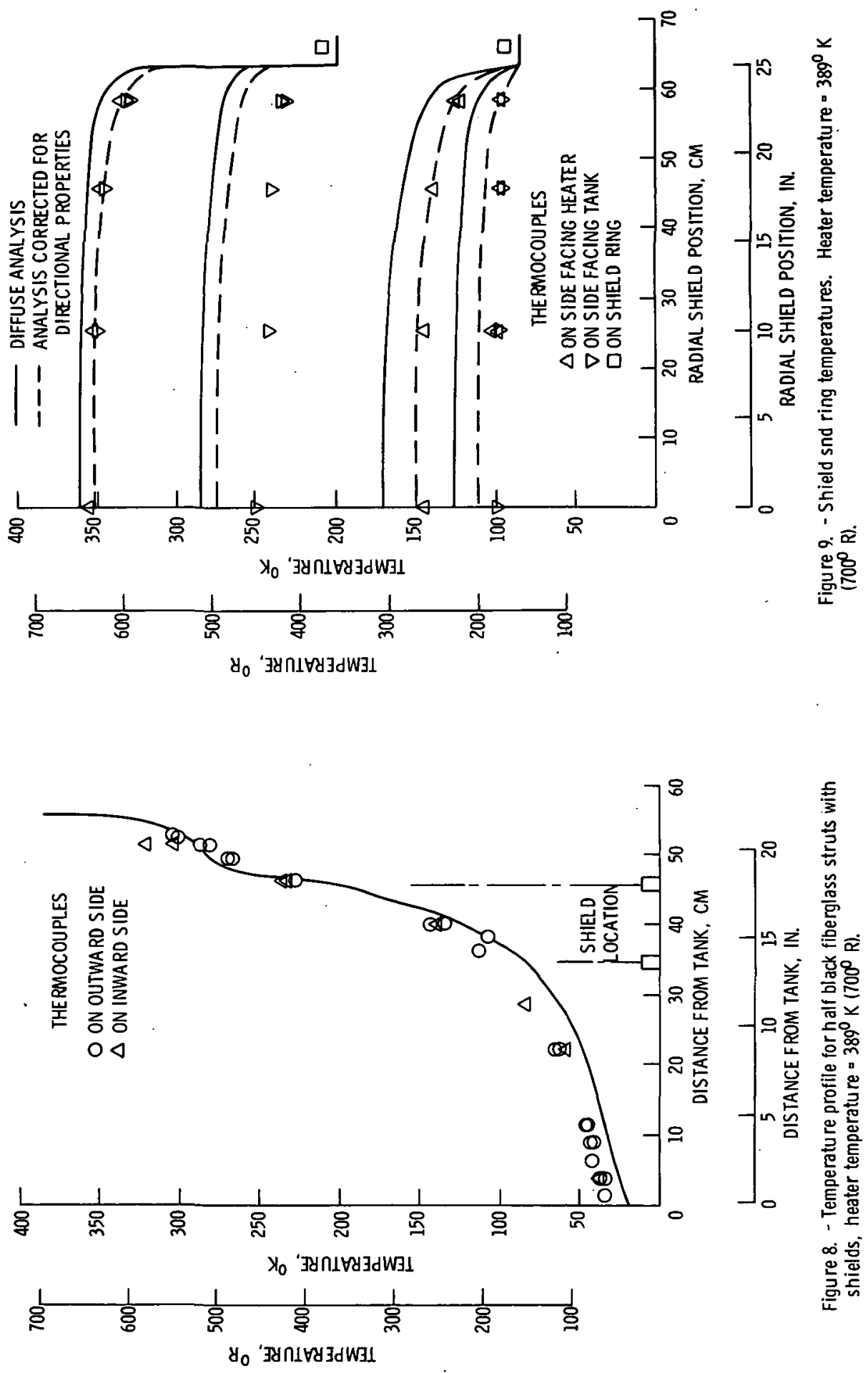